\title{
Interfacing of PV Array with AC Grid using Twelve Pulse Converter
}

\author{
${ }^{* 1}$ Yasir Sheikh, ${ }^{2}$ Sudarshan Khond, ${ }^{3}$ Dr. M. M. Renge \\ 1,2,3 Shri Ramdeobaba College of Engineering and Management, Nagpur \\ Email: ${ }^{1}$ sheikhmn@rknec.edu, ${ }^{2}$ khondsr1@rknec.edu, ${ }^{3}$ rengemm@rknec.edu
}

Received: 06th October 2019, Accepted: 20th November 2019, Published: 31st December 2019

\begin{abstract}
Owing to continuously booming energy demand, if the reliance is on fossil fuel only then energy crunch is very near within few decades. To explore renewable green energy sources is the empirical solution which can dodge the energy crunch. In order to bridge the energy gap, solar energy is used widely. In interfacing of grid with voltage source inverter, the pivotal concern is Synchronization. In the proposed scheme, interfacing of solar PV panels and Ac grid is implemented using line commutated twelve pulse converter and it does not necessitate additional synchronizing circuit. The performance of PV array is affected by variation in irradiance and temperature. As a consequence, the Maximum Power Point (MPP) also shifts. A Maximum Power Point Tracking (MPPT) controller is modelled in order to utilize maximum power from PV array. It is developed by using hill climbing (Perturb and Observe) method.
\end{abstract}

\section{Keywords}

Photovoltaic (PV) Array, AC Grid, MPPT, Twelve-pulse Converter

\section{Introduction}

Solar energy is growing in popularity in electricity generation being clean, affordable, and sustainable. Thus, it is an apt replacement of conventional energy sources that have serious environmental issues. The energy produced by solar radiation is in Direct Current (DC) form. This DC need to be converted into AC form as most of the electrical appliances work on Alternating Current (AC). The most popular device to convert DC into AC is Voltage Source Inverter (VSI). Most Popular topology utilised for interfacing PV array with grid is Voltage source inverter (VSI). The quality of power injected is improved by using two-level VSI with help of PWM techniques [3][4]. For high power, in order to minimise switching losses there is restriction on switching frequency in PWM technology. Further to inject high quality power in grid at low switching frequency [5][6]. Some other configurations are demonstrated in [7] which can be effective for grid interfaced PV applications. These converters need separate frequency synchronizing controllers. Synchronization of grid is pivotal task in interfacing of converters with the grid. The information regarding phase angle of grid voltage is required to transfer the power from converters in synchronization. The techniques used to maintain synchronism are Fourier analysis techniques, Phase Locked Loop, etc. [8]. However there is always change in voltage and frequency. VSI needs to follow frequency changes and synchronization.

In a HVDC, two independent adjacent systems having unlike and conflicting electrical parameters (Frequency / Voltage Level / Short-Circuit Power Level) are connected via a DC link in back-to-back configuration. The conversion $\mathrm{AC}$ to $\mathrm{DC}$ and vice-versa with help of converter valves is the basic principle of operation of HVDC system. There is no need of synchronization and to follow changes in frequency and voltage.

\section{Proposed Scheme}

Block diagram of the proposed grid-connected photovoltaic (PV) array using Twelve-pulse-converter is shown in Fig. 1. An easy scheme utilizing a Twelve-pulse-converter has been implemented for interfacing solar PV array with $\mathrm{AC}$ grid. On the basis power demand, the number of PV panels required in series and in parallel are computed. The turns ratio for transformer connected in star-star is 1:1 and for transformer connected in stardelta is $1: \sqrt{ } 3$. 


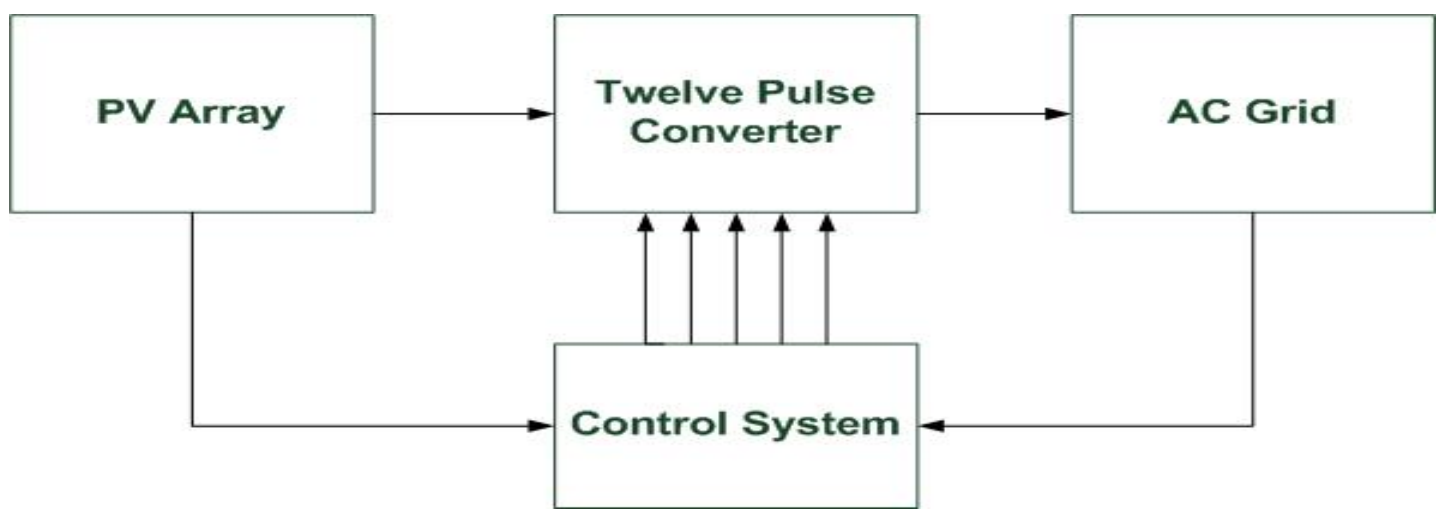

Figure 1: Proposed Scheme

Twelve pulse Converter:

It is proved that there is great improvement in the performance of the converter by increasing pulse number. A six-pulse converter is obtained by suitably connecting two three-pulse converters. The fifth and seventh harmonics in input current are eliminated in twelve pulse converter. Also, the layout of smoothing inductance is reduced due increase in pulse number which minimizes the ripple in output. The improvement of distortion factor leads to improvement of power factor. A rectification mode for firing angle $\left(\alpha<90^{\circ}\right)$ or an inverter mode for firing angle $\left(\alpha>90^{\circ}\right)$ are the modes of operation of a line commuted twelve pulse converter [1]. In the proposed scheme, it is working as inverter with firing angle $\alpha=159^{\circ}$ and power is injected to AC grid as PV array is present in dc side.

Photovoltaic Array:

Photovoltaic cells and panels convert the solar energy into direct-current (DC) electricity. The panels in an array can be linked electrically either in a series, a parallel, or a mixture of the two. But in order to obtain increased value of output voltage series connection is preferred. The graph in Fig. 2 shows the I x V curve of a typical PV cell functioning during normal conditions. The multiplication of current and voltage ( $\mathrm{I} \mathrm{x} \mathrm{V)} \mathrm{gives} \mathrm{solar} \mathrm{cell}$ generated power. The power curve above is a result of point to point multiplication of current and voltages for all voltages considering a fixed radiation level.

MPPT:

Environmental conditions easily affect the performance of PV array. The open-circuit voltage shows substantial reliance on temperature of the cell while short-circuit current changes linearly with the solar irradiance level. As a result, the operating point which satisfies the Maximum Power Point (MPP) condition also varies with the environmental conditions. Thus, it is essential to have a Maximum Power Point Tracking (MPPT) mechanism, which is a control algorithm that can track the MPP continuously during the operation in order to increase the power production of PV system. There are number of methods available to track the maximum power point. The methods which are used popularly are Perturb and observe (hill climbing method), Incremental Conductance method, Fractional short circuit Current, Fractional open circuit voltage, neural networks, Fuzzy logic [9]. Hill climbing method is the simplest method. This method observes power of PV array by changing the supplied voltage. If there is increase in power due to increasing voltage then further firing angle $\alpha$ is incremented otherwise start decrementing the firing angle $\alpha$. This is continued till maximum power point is detected. Developed MPPT controller varies firing angle $\alpha$, there by varying the array voltage. In Fig. 2, the P-V curve shows the shifting of operating point from A to C. At point B, the MPP is detected at firing angle $\alpha=159^{\circ}$. 


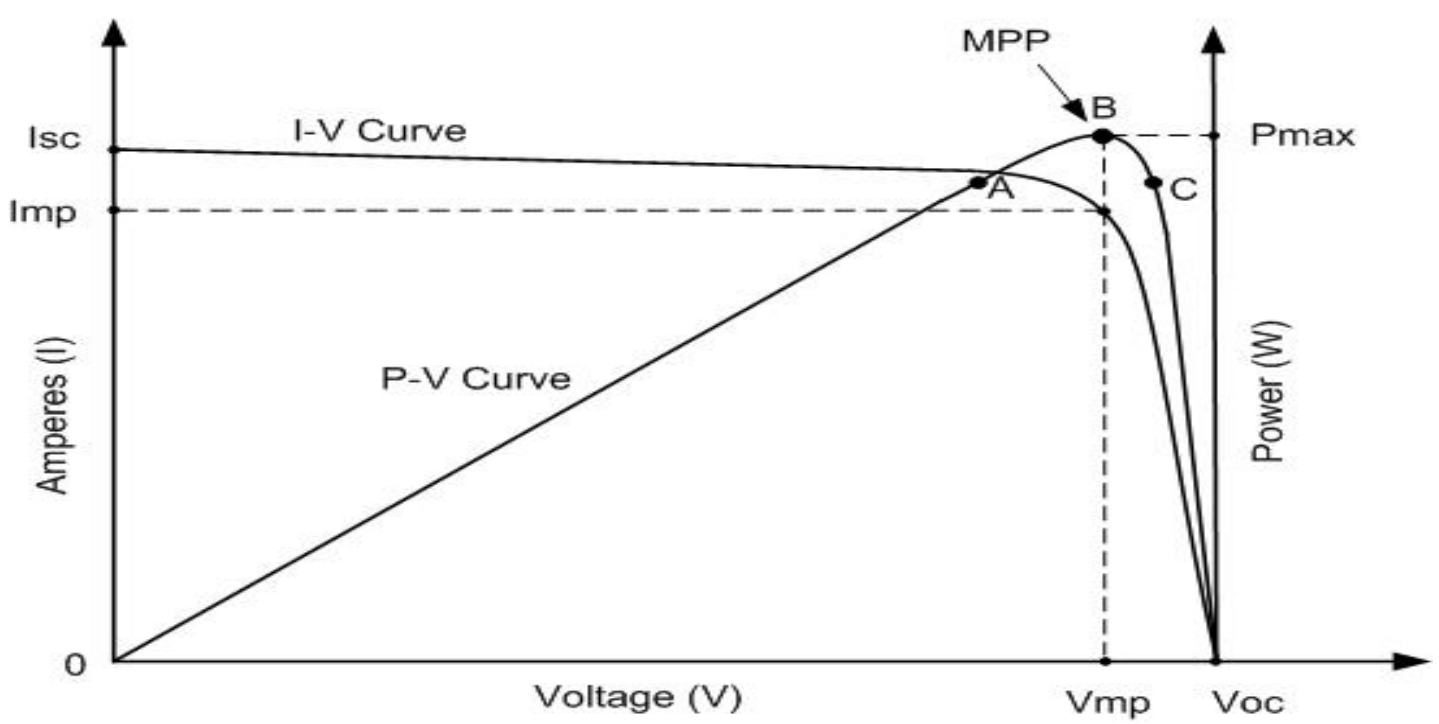

Figure 2: PV Array Characteristics

Methodology

Simulation Architecture

Architecture of simulated PV array interfaced to grid is shown in Fig. 3. An easy scheme utilizing a three phase twelve pulse line commuted inverter has been implemented in which an AC grid is interfaced with solar PV array. Modelling of the PV array is done to transfer $24 \mathrm{KW}$ power at ac grid. According to that, total value of modules to be connected in parallel as well as in series is estimated to meet required power rating. The proposed scheme is carried out for $1000 \mathrm{~W} / \mathrm{m}^{2}$ constant irradiance.

Simulation study has been carried out to get the I-V characteristics of the solar photovoltaic module. The model (Waaree Energies WU-240) is selected to generate I-V characteristic of solar photovoltaic module from one dimensional (1-D) look up table in MATALAB/Simulink. Model's aim is to achieve an I-V curve similar to the graph that presents the manufacturer datasheet of solar panel.

In the proposed scheme, the converter is operated as an inverter. A gate triggering mechanism is designed in order to generate gate pulses to fire each SCR at regular interval of $30^{\circ}$. This mechanism detects the firing instant with the help of sensed voltages of incoming phase and outgoing phase in conducting sequence.

A Maximum Power Point Tracking (MPPT) mechanism is developed, which is a control algorithm which can track the Maximum Power Point (MPP) continuously during the operation in order to maximize the power production of the PV system. The control algorithm is developed by using Hill Climbing method (P and $\mathrm{O}$ method). This MPPT mechanism controls firing angle to get the MPP.

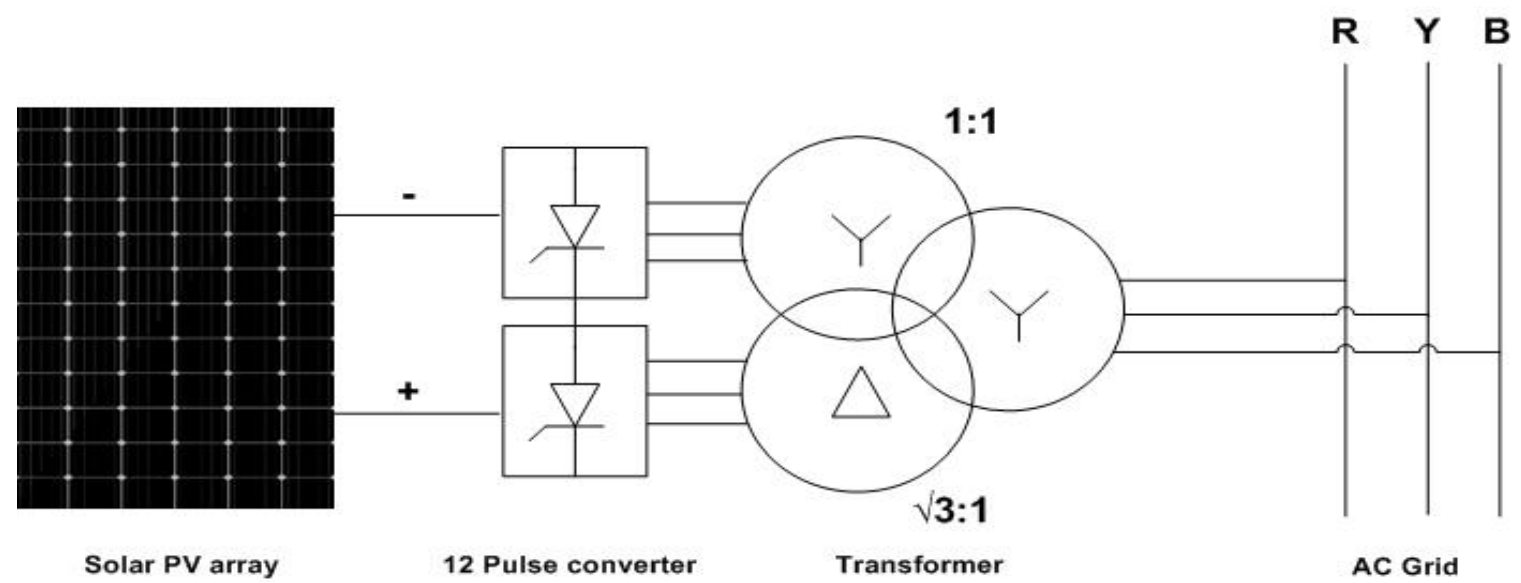

Figure 3: Configuration of Simulated architecture 
Simulation Results:
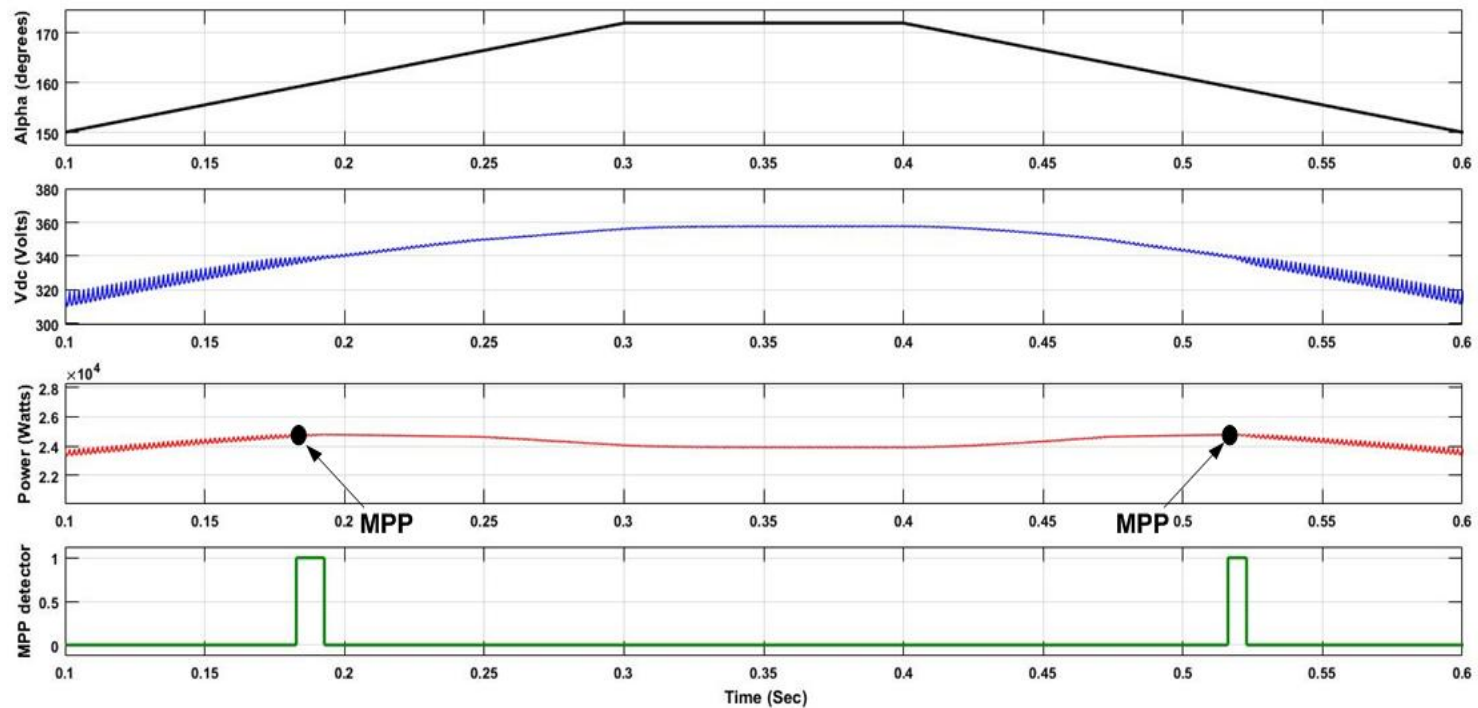

Figure 4: DC Voltage (V $V_{d c}$, Power Delivered by PV Array (P) and Firing Angle Alpha ( $\alpha$ ) without Firing Angle Controller
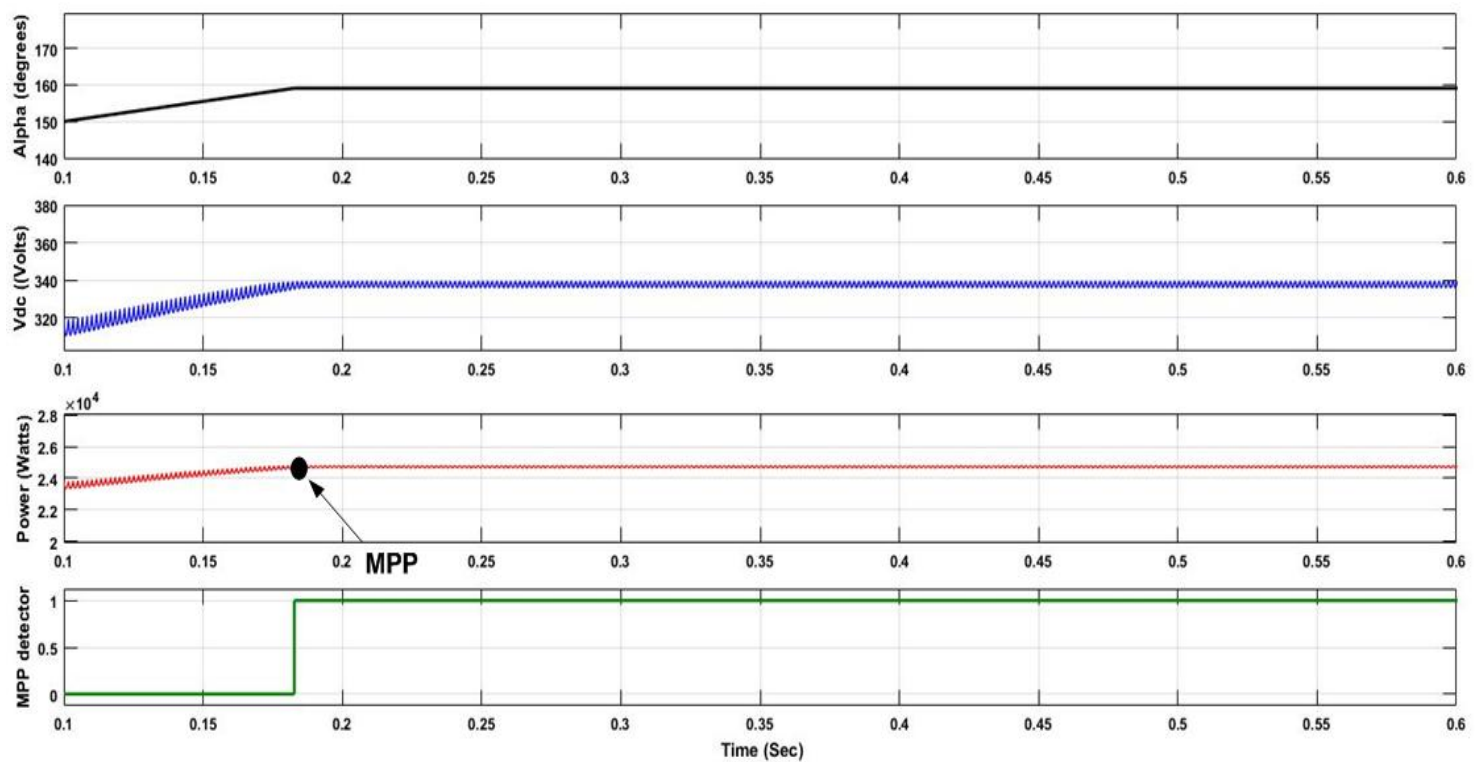

Figure 5: DC Voltage (Vdc), Power Delivered by PV Array (P) and Firing Angle Alpha ( $\alpha$ ) with Firing Angle Controller

\section{Discussion}

To examine the effectiveness of the proposed scheme, simulation is performed by varying the firing angle $(\alpha)$ in the range $150^{\circ}$ to $172^{\circ}$. Fig. 4 shows the PV array voltage $\left(V_{d c}\right)$, power delivered by it $(P)$ and firing angle $(\alpha)$ without controller. The variation in the firing angle $(\alpha)$ also leads to variation in MPP. In order to maximize power delivered by PV array the firing angle should be kept constant at MPP. This is achieved by designing the MPPT controller. Controller continuously senses power and voltage at a particular instant. It evaluates change in power output by PV array with respect to change voltage of the array $(d P / d V)$. A pulse is generated once the instant corresponding to zero change in power for same amount of change in voltage. The same pulse is used to 
hold the value of $\alpha$ which is increasing or decreasing to consider the effect of change in temperature in the simulation. Thus, it is observed in simulation that the $\alpha$ settles at the value corresponding to voltage which will result in maximum power from PV array Fig. 5 shows $\mathrm{PV}$ array voltage $\left(\mathrm{V}_{\mathrm{dc}}\right)$, power delivered by it $(\mathrm{P})$ and firing angle $(\alpha)$ with controller. The firing angle is kept constant at MPP which results in PV array operating at maximum power point.

\section{Conclusion}

The simulated results are compared and verified with the theoretical results to validate the proposed methodology for interfacing of PV array to ac grid. There is no need of additional synchronizing circuit to maintain synchronism and track the grid voltage waveform. The simulated results showed that the MPPT mechanism developed is effective and easy to track the MPP.

\section{References}

1. J. M. Kumbhare, M. M. Renge. 2014. Line commutated Converter for grid interfacing of solar photovoltaic array. IEEE International Conference on Power Electronics, Drives and Energy.

2. Bimal K. Bose.2000. Energy, Environment, and Advances in Power Electronics. IEEE Trans. on Power Electronics 15:688- 701.

3. Bin Wu. 2006. High-Power Converters and AC Drives. IEEE press.

4. Mateus F. Schonardie and Denizar C. Martins. 2007. Solar grid-connected three-phase system with active and reactive power control and input voltage clamped. 14th IEEE International Conference on Electronics, Circuits and Systems 463-466.

5. Javier Chavarria, Domingo Biel, Francesc Guinjoan, Carlos Meza and Juan J. Negroni. 2013. Energy-Balance Control of PV Cascaded Multilevel Grid-Connected Inverters Under Level-Shifted and Phase-Shifted PWMs. IEEE Trans. on Industrial Electronics 60:98-111.

6. Javier Echeverria, Samir Kouro, Marcelo Perez and Haitham Abu-Rub. 2013. Multi-Modular Cascaded DCDC Converter for HVDC Grid Connection of Large-Scale Photovoltaic Power Systems. 39th Annual IEEE Conference on Industrial Electronics Society 6999-7005.

7. Sachin Jain and Vivek Agrawal. 2007. A Single-Stage Grid Connected Inverter Topology for Solar PV Systems With Maximum Power Point Tracking. IEEE Trans. on Power Elecronics. 22:1928-1940.

8. Remus Teodorescu, Marco Liserre and Pedro Rodriguez. 2011. Grid converter for photovoltaic and Wind Power System. First edition, John Wiley and Sons Ltd.

9. Bidyadhar Subudhi and Raseswari Pradhan. 2013. A Comparative Study on Maximum Power Point Tracking Techniques for Photovoltaic Power Systems. IEEE Trans. on Sustainable Energy. 4:89-98. 